\title{
Preoperative statins for the prevention of atrial fibrillation after cardiothoracic surgery
}

\author{
Kirkeith Lertsburapa, MD, ${ }^{a}$ C. Michael White, PharmD, ${ }^{b}$ Jeffrey Kluger, MD, ${ }^{a}$ Osman Faheem, MD, ${ }^{c}$ \\ Jonathon Hammond, MD, ${ }^{d}$ and Craig I. Coleman, PharmD ${ }^{\mathrm{e}}$
}

From the Henry Low Heart Center, Hartford Hospital, ${ }^{\mathrm{a}}$ Hartford, Conn; University of Connecticut School of Pharmacy, Cardiac Pharmacology Service, Divisions of Cardiology and Drug Information, ${ }^{\text {b }}$ Hartford, Conn; University of Connecticut School of Medicine, Department of Internal Medicine, Hartford Hospital, ${ }^{\mathrm{c}}$ Hartford, Conn; Divisions of Cardiology and Cardiothoracic Surgery, Hartford Hospital, Hartford, Conn'; and University of Connecticut School of Pharmacy, ${ }^{\mathrm{e}}$ Storrs, Conn.

This study was supported by The Patrick and Catherine Weldon Donaghue Medical Research Foundation, West Hartford, Conn. None of the investigators have conflicts of interest to report.

Received for publication April 5, 2007; revisions received Aug 21, 2007; accepted for publication Aug 30, 2007.

Address for reprints: Craig I. Coleman, PharmD, University of Connecticut School of Pharmacy, Pharmacy Practice, 80 Seymour Street, CB309, Hartford, CT 06102 (E-mail: ccolema@harthosp.org).

J Thorac Cardiovasc Surg 2008;135:405-11 0022-5223/\$34.00

Copyright $\odot 2008$ by The American Association for Thoracic Surgery

doi:10.1016/j.jtcvs.2007.08.049
Objective: Recent studies have suggested that statins reduce atrial fibrillation after cardiothoracic surgery, but the use of proven prophylactic strategies such as betablockers and amiodarone in these studies was not provided. Therefore, we sought to determine whether preoperative statin use could reduce the incidence of postcardiothoracic surgery atrial fibrillation in a population who already had a high background use of beta-blockers and appreciable use of prophylactic amiodarone.

Methods: Patients undergoing cardiothoracic surgery from the randomized, controlled Atrial Fibrillation Suppression Trials I, II, and III were evaluated in this nested cohort evaluation. The patients' demographics, surgical characteristics, medication use, and incidence of post-cardiothoracic surgery atrial fibrillation (atrial fibrillation $>5$ minutes duration) were uniformly and prospectively collected as part of Atrial Fibrillation Suppression Trials I, II, and III. Multivariate logistic regression was used to calculate adjusted odds ratios with $95 \%$ confidence intervals.

Results: Overall, 331 patients $(59.6 \%)$ received a statin preoperatively and 224 patients $(40.4 \%)$ did not. The study population had an average age of $67.8 \pm 8.6$ years, $77.1 \%$ were male, $14.6 \%$ had valve surgery, $6.1 \%$ had a history of atrial fibrillation, $12.6 \%$ had a history of heart failure, $84.0 \%$ received postoperative beta-blockade, and $44.1 \%$ received postoperative prophylactic amiodarone. In total, 174 patients (31.4\%) developed post-cardiothoracic surgery atrial fibrillation. Upon multivariate logistic regression, statin use was associated with a reduction in postcardiothoracic surgery atrial fibrillation (adjusted odds ratio: 0.60; 95\% confidence interval $0.37-0.99$ ). Higher intensity statin dosing (equivalent of $\geq 40 \mathrm{mg}$ of atorvastatin) seemed to be associated with the greatest reductions in post-cardiothoracic surgery atrial fibrillation (adjusted odds ratio: 0.45 ; 95\% confidence interval $0.21-$ $0.99)$.

Conclusions: In a population with appreciable beta-blocker and amiodarone use, adjunctive preoperative statin use was still associated with a $40 \%$ reduction in patients' odds of developing post-cardiothoracic surgery atrial fibrillation.

A pproximately 666,000 cardiothoracic surgeries (CTS) were performed in the United States in 2003. ${ }^{1}$ One of the most common complications after CTS is the development of atrial fibrillation (AF). Although typically self limiting, post-CTS AF can increase a patient's risk for hemodynamic instability and stroke. ${ }^{2}$ Moreover, it prolongs the length of stay and increases total hospital costs. ${ }^{2,3}$ Betablockers and amiodarone are thus commonly used to prevent post-CTS AF and have been effective according to a recent meta-analysis. ${ }^{4}$ Even with prophylactic beta-blockade and/or amiodarone, up to $40 \%$ of patients still develop post-CTS $\mathrm{AF}^{4-7}$

Given the antiadrenergic effects of beta-blockers and amiodarone, the risks of hypotension, bradycardia, and heart block are elevated. Additional adjunctive strategies to further impede sympathetic functioning will likely exacerbate these adverse events; therefore, a novel strategy for reducing post-CTS AF is required. 


\section{Abbreviations and Acronyms \\ $\mathrm{AF}=$ atrial fibrillation \\ $\mathrm{CI}=$ confidence interval \\ $\mathrm{CTS}=$ cardiothoracic surgery}

Inflammation may be a causative factor in the development of postoperative and nonsurgical $\mathrm{AF}^{8-11}$ Given the ability of statins to attenuate inflammation, ${ }^{12-14}$ previous studies have assessed the relationship between statin use pre-CTS and the subsequent development of AF after surgery. ${ }^{15-18}$ Unfortunately, none of these studies assessed statin efficacy when added to appreciable prophylaxis with beta-blockers and amiodarone. Whether statins would still maintain efficacy when added to a population receiving higher levels of prophylactic beta-blockers and amiodarone is not known.

By combining the patient data from 3 randomized and controlled clinical trials, the Atrial Fibrillation Suppression Trials (AFIST) I, II, and III, ${ }^{6,7,19}$ we had 555 patients who had undergone CTS from whom to conduct a "nested" study. All of the data were prospectively determined during the trials, end point definitions were the same, postoperative beta-blocker administration was high, and use of prophylactic amiodarone was substantial. We therefore examined the impact of preoperative statin use on the incidence of postoperative AF in this nested population.

\section{Materials and Methods Design and Population}

Our study prospectively evaluated a nested cohort of 555 patients who underwent coronary artery bypass grafting and/or valvular surgery as part of the AFIST I, II, and III. This study was approved by the Hartford Hospital Institutional Review Committee after expedited review.

AFIST $\mathrm{I}^{6}$ was a randomized, double-blind, placebo-controlled trial that assessed the effect of oral amiodarone or placebo on the incidence of AF after cardiac surgery $(n=217)$. Patients enrolled less than 5 days before surgery received $6 \mathrm{~g}$ of amiodarone or placebo during 6 days beginning on preoperative day 1. Patients enrolled at least 5 days before surgery received $7 \mathrm{~g}$ during 10 days beginning on preoperative day 5 . AFIST $\mathrm{II}^{7}$ was a $2 \times 2$ factorial study that assessed the effect of 2 active treatments (amiodarone and atrial septal pacing) on the incidence of AF after cardiac surgery $(n=160)$. Patients were initially randomized to either amiodarone or placebo and then randomized further to either atrial septal pacing or no pacing. AFIST III ${ }^{19}$ was a randomized controlled trial that assessed the effect of aortic fat pad maintenance on the incidence of postoperative AF in patients $(n=178)$ undergoing coronary artery bypass graft surgery for the first time.

Data with respect to patient demographics, surgical characteristics, medication use, and postoperative AF were prospectively and uniformly collected as part of AFIST I, II, and III. In AFIST I, II, and III, the primary end point was the development of post-CTS
AF within 30 days of cardiac surgery. AF was defined as episodes lasting more than 5 minutes as documented by continuous telemetry. Statin use and dose were recorded. The statins were converted to atorvastatin equivalents using the following conversions: atorvastatin $10 \mathrm{mg}=$ simvastatin $5-20 \mathrm{mg}$, lovastatin $10-40 \mathrm{mg}$, pravastatin $10-40 \mathrm{mg}$, fluvastatin $20-80 \mathrm{mg}$, or cerivastatin $0.1-0.4 \mathrm{mg}$; atorvastatin $20 \mathrm{mg}=$ simvastatin $40 \mathrm{mg}$, pravastatin $80 \mathrm{mg}$; rosuvastatin $5 \mathrm{mg}$, or cerivastatin $0.8 \mathrm{mg}$; atorvastatin $40 \mathrm{mg}=\operatorname{simvastatin} 80$ $\mathrm{mg}$ or rosuvastatin $10 \mathrm{mg}$; atorvastatin $80 \mathrm{mg}=$ rosuvastatin 20 mg. ${ }^{20-22}$

\section{Statistical Analysis}

Continuous variables are presented as means with standard deviations and were compared between groups using a Student $t$ test or Mann-Whitney test when appropriate. Dichotomous variables are presented as percentages and were compared between groups using a chi-square or Fisher exact test when appropriate.

Because this was an observational study, the investigators had no control over which patients received statins. As a result, significant differences in observed demographic, surgical, and medication use characteristics were expected. To control for these potential confounders and to avoid a biased estimate of treatment effect, we conducted a multivariate logistic regression. Univariate analysis was first performed to examine the relationship between different variables (demographic, surgical, and medication use characteristics) and the development of postoperative AF (dependent variable). All variables that showed a univariate association $(P \leq .20)$ with AF occurrence or that were previously demonstrated to be strong independent predictors of $\mathrm{AF}^{3,6,7,19,23,24}$ were then entered into a backward, stepwise multivariate regression model. Adjusted odds ratios and $95 \%$ confidence intervals (CIs) were calculated for all independent predictors. Statistical analysis was performed with the Statistical Package for the Social Sciences version 15.0 (SPSS Inc, Chicago, Ill).

\section{Results}

A total of 555 patients were evaluated, of whom 331 $(59.6 \%)$ received a statin preoperatively and $224(40.4 \%)$ did not. Overall, the study population had an average age of $67.8 \pm 8.6$ years, $77.1 \%$ were male, $14.6 \%$ had valve surgery, $6.1 \%$ had a history of AF, $12.6 \%$ had a history of heart failure, $84.0 \%$ received postoperative beta-blockade, and $44.1 \%$ received prophylactic amiodarone. Table 1 depicts the results of univariate comparisons of demographic and perioperative characteristics between patients receiving and not receiving a statin. Similarly, comparisons of demographics and perioperative characteristics between patients developing and not developing post-CTS AF are provided in Table 2 .

In total, 174 patients $(31.4 \%)$ developed $\mathrm{AF}$ after cardiac surgery $(36.6 \%$ vs $27.8 \%$ in the non-statin and statin groups, respectively; crude odds ratio: 0.68 ; 95\% CI: 0.46-0.96). Of the 174 patients, only 1 developed AF after discharge but within 30 days. On multivariate analysis (Table 3), the preoperative use of statins was associated with a statistically significant reduction in AF (adjusted odds ratio: 0.60; 95\% CI: 0.37-0.99). Benefit was also seen with nonsteroidal, 
TABLE 1. Patient demographics, surgical characteristics, and medication use by statin use

\begin{tabular}{|c|c|c|c|}
\hline \multirow[b]{2}{*}{ Variable } & \multirow{2}{*}{$\frac{\text { No statin }(n=224)}{n(\%)}$} & \multirow{2}{*}{$\frac{\text { Statin }(n=331)}{n(\%)}$} & \multirow[b]{2}{*}{$P$ value } \\
\hline & & & \\
\hline \multicolumn{4}{|l|}{ Preoperative characteristics } \\
\hline Age, y (mean \pm SD) & $69.4 \pm 8.7$ & $66.7 \pm 8.4$ & $<.001$ \\
\hline Male gender & $172(76.8)$ & $256(77.3)$ & .88 \\
\hline Participant in AFIST I & $118(52.8)$ & $99(29.9)$ & $<.001$ \\
\hline Participant in AFIST II & $59(26.3)$ & $101(30.5)$ & .29 \\
\hline Participant in AFIST III & $47(21.0)$ & $131(39.6)$ & $<.001$ \\
\hline History of diabetes mellitus & $64(28.6)$ & $120(36.3)$ & .06 \\
\hline History of hypertension & $156(69.6)$ & $253(76.4)$ & .08 \\
\hline History of smoking & $132(58.9)$ & $194(58.6)$ & .94 \\
\hline History of myocardial infarction & $69(30.8)$ & $136(41.1)$ & .01 \\
\hline Family history of CAD & $84(37.5)$ & $133(40.2)$ & .53 \\
\hline History of angina & $158(70.5)$ & $250(75.5)$ & .19 \\
\hline History of heart failure & $34(15.2)$ & $36(10.9)$ & .13 \\
\hline $\mathrm{EF}, \%($ mean $\pm \mathrm{SD})$ & $49.2 \pm 13.1$ & $50.2 \pm 12.1$ & .46 \\
\hline$>45$ & $137(61.6)$ & $204(61.6)$ & .40 \\
\hline $25-45$ & $77(34.4)$ & $119(36.0)$ & \\
\hline$<25$ & $10(4.5)$ & $8(2.4)$ & \\
\hline Prior $\mathrm{AF}$ & $13(5.8)$ & $21(6.3)$ & .79 \\
\hline History of cerebrovascular disease & $11(4.9)$ & $16(4.8)$ & .97 \\
\hline History of COPD & $33(14.7)$ & $43(13.0)$ & .56 \\
\hline History of mitral regurgitation & $58(25.9)$ & $54(16.3)$ & .01 \\
\hline Vessels $>50 \%$ occluded & $2.6 \pm 1.1$ & $2.9 \pm 0.8$ & .003 \\
\hline \multicolumn{4}{|l|}{ Preoperative medical therapy } \\
\hline Beta-blocker & $145(64.7)$ & $264(79.8)$ & $<.001$ \\
\hline CCB & $48(21.4)$ & $49(14.8)$ & .04 \\
\hline Digoxin & $12(5.4)$ & $16(4.8)$ & .78 \\
\hline ACEI or ARB & $96(42.9)$ & $168(50.8)$ & .08 \\
\hline \multicolumn{4}{|l|}{ Surgical characteristics } \\
\hline Valve surgery & $51(22.8)$ & $30(9.1)$ & $<.001$ \\
\hline On-pump surgery & $166(74.1)$ & $207(62.5)$ & .004 \\
\hline Duration of surgery, min, (mean \pm SD) & $289.4 \pm 87.0$ & $290.8 \pm 104.5$ & .87 \\
\hline No. of grafts, $n$, (mean \pm SD) & $3.5 \pm 1.8$ & $3.9 \pm 1.4$ & .005 \\
\hline No. of arterial Grafts, $n$, (mean \pm SD) & $1.4 \pm 1.2$ & $1.8 \pm 1.2$ & $<.001$ \\
\hline No. of venous grafts, $n$, (mean \pm SD) & $2.2 \pm 1.5$ & $2.2 \pm 1.3$ & .81 \\
\hline \multicolumn{4}{|l|}{ Postoperative medication use } \\
\hline Amiodarone & $101(45.1)$ & $144(43.5)$ & .71 \\
\hline Beta-blocker & $180(80.4)$ & $286(86.4)$ & .06 \\
\hline ССВ & $17(7.6)$ & $37(11.2)$ & .16 \\
\hline Digoxin & $73(32.6)$ & $74(22.4)$ & .007 \\
\hline Corticosteroids & $77(34.4)$ & $71(21.5)$ & .001 \\
\hline NSAIDs & $54(24.1)$ & $73(22.1)$ & .57 \\
\hline ACEI/ARB & $86(38.4)$ & $132(39.9)$ & .73 \\
\hline Beta-blocker withdrawal & $18(8.0)$ & $32(9.7)$ & .51 \\
\hline ACEI/ARB withdrawal & $35(15.6)$ & $68(20.5)$ & .14 \\
\hline
\end{tabular}

$S D$, Standard deviation; $A F I S T$, Atrial Fibrillation Suppression Trial; $C A D$, coronary artery disease; $E F$, ejection fraction; COPD, chronic obstructive pulmonary disease; $C C B$, calcium channel blocker; $A C E I$, angiotensin converting enzyme inhibitor; $A R B$, angiotensin receptor blocker; NSAID, nonsteroidal anti-inflammatory drug.

preoperative beta-blocker, and prophylactic amiodarone administration ( $P \leq .04$ for all). Age, number of arterial grafts, beta-blocker withdrawal (patient treated with preoperative beta-blocker but not receiving postoperative beta-blocker before onset of $\mathrm{AF}$ ), and histories of $\mathrm{AF}$, diabetes mellitus, and mitral valve regurgitation were positive risk factors for developing AF after surgery ( $P \leq .04$ for all).

When subgroup analysis evaluating the impact of different statin dosing intensities was performed, statin doses equivalent to $\geq 40 \mathrm{mg}$ per day of atorvastatin resulted in 
TABLE 2. Patient demographics, surgical characteristics, and medication use by postoperative cardiothoracic surgery atrial fibrillation status

\begin{tabular}{|c|c|c|c|}
\hline \multirow[b]{2}{*}{ Variable } & \multirow{2}{*}{$\frac{\text { No post-CTS AF }(n=381)}{n(\%)}$} & \multirow{2}{*}{$\frac{\text { Post-CTS AF (n = 174) }}{n(\%)}$} & \multirow[b]{2}{*}{$P$ value } \\
\hline & & & \\
\hline \multicolumn{4}{|l|}{ Preoperative characteristics } \\
\hline Age, y (mean \pm SD) & $66.7 \pm 8.5$ & $70.2 \pm 8.4$ & $<.001$ \\
\hline Male gender & $301(79.0)$ & $127(73.0)$ & .12 \\
\hline Participant in AFIST I & $153(40.2)$ & $64(36.8)$ & .45 \\
\hline Participant in AFIST II & $111(29.1)$ & $49(28.2)$ & .81 \\
\hline Participant in AFIST III & $117(30.7)$ & $61(35.1)$ & .31 \\
\hline History of diabetes mellitus & $118(31.0)$ & $66(37.9)$ & .11 \\
\hline History of hypertension* & $280(73.5)$ & $129(74.1)$ & .87 \\
\hline History of smoking* & $228(59.8)$ & $98(56.3)$ & .43 \\
\hline History of myocardial infarction* & $139(36.5)$ & $66(37.9)$ & .74 \\
\hline Family history of CAD & $149(39.1)$ & $68(39.1)$ & $>.99$ \\
\hline History of angina & $288(75.6)$ & $120(69.0)$ & .10 \\
\hline History of heart failure & $37(9.7)$ & $33(19.0)$ & .002 \\
\hline $\mathrm{EF}, \%(\text { mean } \pm \mathrm{SD})^{*}$ & $50.3 \pm 12.6$ & $49.1 \pm 12.3$ & .31 \\
\hline$>45$ & $238(62.5)$ & $103(59.2)$ & .22 \\
\hline $25-45$ & $128(33.6)$ & $68(39.1)$ & \\
\hline$<25$ & $15(3.9)$ & $3(1.7)$ & \\
\hline Prior AF & $15(3.9)$ & $19(10.9)$ & $<.001$ \\
\hline History of cerebrovascular disease & $17(4.5)$ & $10(5.7)$ & .51 \\
\hline History of COPD & $45(11.8)$ & $31(17.8)$ & .06 \\
\hline History of mitral regurgitation & $64(16.8)$ & $48(27.6)$ & .003 \\
\hline Vessels $>50 \%$ occluded & $2.8 \pm 0.9$ & $2.6 \pm 1.1$ & .07 \\
\hline \multicolumn{4}{|l|}{ Preoperative medical therapy } \\
\hline Statin & $142(37.3)$ & $82(47.1)$ & .04 \\
\hline Beta-blocker & $291(76.4)$ & $118(67.8)$ & .03 \\
\hline CCB & $63(16.5)$ & $34(19.5)$ & .39 \\
\hline Digoxin & $16(4.2)$ & $12(6.9)$ & .18 \\
\hline ACEl/ARB & $182(47.8)$ & $82(31.1)$ & .89 \\
\hline \multicolumn{4}{|l|}{ Surgical characteristics } \\
\hline Valve surgery & $42(11.0)$ & $39(22.4)$ & $<.001$ \\
\hline On-pump surgery* & $258(67.7)$ & $115(66.1)$ & .71 \\
\hline Duration of surgery, min, (mean $\pm S D$ ) & $283.9 \pm 81.9$ & $304.1 \pm 124.8$ & .02 \\
\hline No. of grafts, n, (mean \pm SD) & $3.8 \pm 1.5$ & $3.7 \pm 1.7$ & .11 \\
\hline No. of arterial grafts, $n,(\text { mean } \pm S D)^{*}$ & $1.6 \pm 1.2$ & $1.6 \pm 1.2$ & .82 \\
\hline No. of venous grafts, $n,($ mean $\pm S D)$ & $2.2 \pm 1.4$ & $2.1 \pm 1.4$ & .28 \\
\hline \multicolumn{4}{|l|}{ Postoperative medication use } \\
\hline Amiodarone & $191(50.1)$ & $54(31.0)$ & $<.001$ \\
\hline Beta-blocker & $327(85.8)$ & $139(79.9)$ & .08 \\
\hline CCB & $31(8.1)$ & $23(13.2)$ & .06 \\
\hline Digoxin & $70(18.4)$ & $77(44.3)$ & $<.001$ \\
\hline Corticosteroids* & $100(26.2)$ & $48(27.6)$ & .74 \\
\hline NSAIDs & $101(26.5)$ & $26(14.9)$ & .003 \\
\hline ACEI/ARB & $147(38.6)$ & $71(40.8)$ & .62 \\
\hline Beta-blocker withdrawal & $28(7.3)$ & $22(12.6)$ & .04 \\
\hline ACEI/ARB withdrawal & $70(18.4)$ & $33(19.0)$ & .87 \\
\hline Statin withdrawal & $54(14.2)$ & $20(11.5)$ & .39 \\
\hline
\end{tabular}

CTS, Cardiothoracic surgery; $A F$, atrial fibrillation; $S D$, standard deviation; $A F I S T$, Atrial Fibrillation Suppression Trial; $C A D$, coronary artery disease; $E F$, ejection fraction; COPD, chronic obstructive pulmonary disease; CCB, calcium channel blocker; $A C E l$, angiotensin converting enzyme inhibitor; $A R B$, angiotensin receptor blocker; $N S A I D$, nonsteroidal, anti-inflammatory drug. *These independent variables were included in the multivariate analysis in addition to the variables with a $P \leq .20$ because of previous evidence they are strong independent predictors of postoperative AF. 
TABLE 3. Results of multivariate logistic regression*

\begin{tabular}{lccr}
\hline Variable & $\begin{array}{c}\text { Total no. of } \\
\text { events/total }\end{array}$ & A0R (95\% CI) & P value \\
\hline Preoperative statin use & $82 / 224(36.6)$ & $0.60(0.37-0.99)$ & .048 \\
Prophylactic amiodarone use & $54 / 245(21.1)$ & $0.36(0.23-0.55)$ & $<.001$ \\
Age (per 10 y) & NA & $1.60(1.33-1.87)$ & $<.001$ \\
History of AF & $19 / 34(55.9)$ & $3.57(1.60-7.80)$ & .01 \\
History of diabetes mellitus & $66 / 184(35.9)$ & $1.70(1.12-2.60)$ & .01 \\
History of mitral valve regurgitation & $48 / 112(39.3)$ & $1.71(1.04-2.83)$ & .04 \\
Preoperative beta-blocker use & $139 / 409(34.0)$ & $0.61(0.38-0.98)$ & .04 \\
No. of arterial grafts (per graft) & NA & $1.22(1.02-1.47)$ & .03 \\
Postoperative nonsteroidal use & $26 / 127(20.5)$ & $0.59(0.35-0.99)$ & .04 \\
Beta-blocker withdrawal & $22 / 50(44.0)$ & $2.17(1.11-4.25)$ & .02 \\
\hline
\end{tabular}

$A O R$, Adjusted odds ratio; $C l$, confidence interval; $A F$, atrial fibrillation; $N A$, not available. ${ }^{*}$ The Hosmer-Lemeshow goodness-of-fit test $\left(\chi^{2}\right.$ test statistic $=6.4$; degrees of freedom $=8 ; P=.58$ ); area under the receiver operator curve $=0.7$.

the greatest reductions in post-CTS AF (55\% reduction) compared with those receiving $\geq 20 \mathrm{mg}$ but less than $40 \mathrm{mg}$ ( $43 \%$ reduction) or less than $20 \mathrm{mg}$ ( $25 \%$ reduction) (Figure 1). In addition, patients receiving the equivalent of at least $20 \mathrm{mg}$ of atorvastatin $(\mathrm{n}=144)$ had a $40 \%$ reduction in the odds of developing post-CTS AF (adjusted odds ratio: 0.60; 95\% CI: 0.23-0.99) versus patients receiving lower equivalent doses of statin or no statin therapy $(n=411)$. When patients receiving the equivalent of at least $20 \mathrm{mg}$ of atorvastatin $(\mathrm{n}=$ 144) were compared with those receiving only low-intensity statin therapy $(\mathrm{n}=187)$, there was a nonsignificant $29 \%$ reduction in post-CTS AF (adjusted odds ratio: 0.71; 95\% CI: 0.41-1.25).

\section{Discussion}

To date, meta-analyses have demonstrated the efficacy of only a few prophylactic strategies to reduce post-CTS AF: beta-blockers, amiodarone, sotalol, magnesium, and biatrial pacing. ${ }^{4,23}$ Although beta-blockers, amiodarone, and sotalol are included in the most recent American College of Cardiology/American Heart Association/European Society of Cardiology practice guidelines for the management of post-CTS $\mathrm{AF}$, only amiodarone and beta-blockers have been shown to be effective and safe when combined. ${ }^{24}$ However, the use of these therapies can increase the risk of hypotension, bradycardia, and heart block, making it unlikely that additional antiadrenergic drugs can be added to this combination regimen.

Inflammation may be a causative factor in the development of post-CTS AF. Bruins and colleagues ${ }^{9}$ documented the presence of an inflammatory process by measuring levels of interleukin- 6 and C-reactive protein early in the postoperative period. Their group demonstrated that these inflammatory markers significantly increased after cardiac surgery, with levels of C-reactive protein peaking around postoperative day 2 and coinciding with the peak incidence of atrial arrhythmias. ${ }^{9}$ The study was rather small, but these findings were complemented by other reports that substantiated the

Figure 1. Effect of statin dosing intensity on the development of postoperative AF. $A F$, Atrial fibrillation.
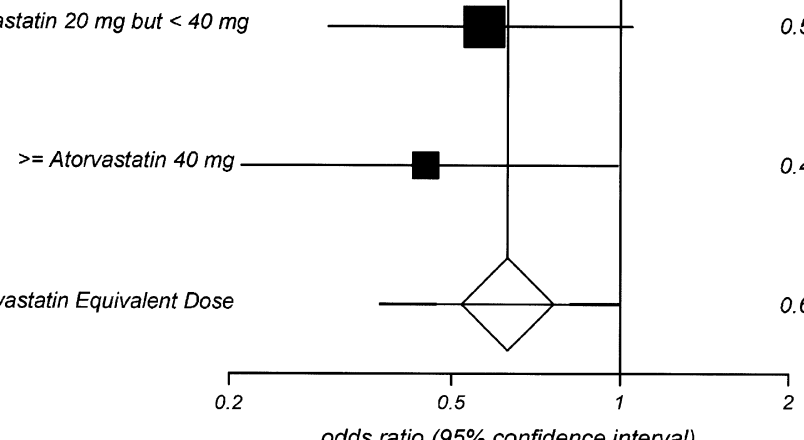

odds ratio ( $95 \%$ confidence interval) 
role of inflammation in the development of both postoperative and nonsurgical AF. ${ }^{8,10,11,18}$ Statins were subsequently found to attenuate this inflammation. Kumagai and colleagues ${ }^{13}$ showed that atorvastatin was able to decrease C-reactive protein levels while diminishing the AF burden in a canine model of sterile pericarditis. Brull and colleagues $^{25}$ noted decreased interleukin- 6 levels in patients who received statins before cardiac surgery.

Past observational studies have reported an association between preoperative statin use and reduced rates of post-CTS AF. ${ }^{15-17}$ ARMYDA-3 was the first clinical trial to evaluate the impact of statin therapy on post-CTS AF. ${ }^{18}$ Two hundred patients undergoing elective CTS were randomized to either atorvastatin $(40 \mathrm{mg} / \mathrm{d}, \mathrm{n}=101)$ or placebo $(\mathrm{n}=99)$ starting 7 days preoperatively. Post-CTS AF occurred in $35 \%$ of patients in the atorvastatin arm and in $57 \%$ of patients in the placebo arm, representing a $61 \%$ reduction $(P=.017)$ in $\mathrm{AF}$ incidence in those who received statins. Before surgery, beta-blockers were used by $72 \%$ and $60 \%$ of patients in the atorvastatin and placebo arms, respectively, whereas amiodarone was administered to only 1 patient in each group. Similar to the observational studies, no information was given regarding the rates of postoperative beta-blocker and amiodarone therapy; the $57 \%$ incidence of post-CTS AF in the placebo group, however, suggests low use of these treatments.

In our study, patients from AFIST I, II, and III received postoperative beta-blockers and amiodarone approximately $84.0 \%$ and $44.1 \%$ of the time, respectively. As expected, the withdrawal of a beta-blocker postoperatively significantly increased the incidence of $\mathrm{AF}$, and the use of prophylactic amiodarone significantly reduced the incidence of $\mathrm{AF}$ after cardiac surgery. Multivariate analysis, however, also demonstrated that statin use before surgery had a positive and independent effect on AF rates. Specifically, patients taking preoperative statins experienced a $40 \%$ reduction in their odds of developing postoperative $\mathrm{AF}$, an effect size comparable to that seen in previous statin studies. ${ }^{16,17}$

Although our study was observational in nature, a number of characteristics helped limit the effects of confounding and biases on our results. The use of "nested" data from the previously conducted, prospective, randomized, and controlled AFIST I, II, and III likely reduced the impact of selection, misclassification, surveillance, and researcher bias. Our use of multivariate logistic regression to calculate adjusted odds ratios likely minimized much of the confounding during statistical analysis. Data on most of the commonly accepted independent predictors of post-CTS AF identified in the American College of Cardiology/American Heart Association/European Society of Cardiology AF guidelines were available for use in the multivariate adjustment. Yet even with these measures, there is some degree of bias that cannot be extracted during observational trials, representing a limitation. It is also important to note that our multivariable analysis may suffer from a mild degree of over-fitting.
Our study has other limitations that should be noted. First, we converted all statins to an equivalent dose of atorvastatin; although this was necessary to facilitate our high- versus lowintensity comparison, it should be noted that antifibrillatory effects might not be identical across all statins. Although we were able to show that higher intensity statin therapy was a negative independent predictor of post-CTS AF versus the combined group receiving either no therapy or lower intensity therapy, we did not have adequate power to evaluate higher intensity versus lower intensity therapy by itself. However, the adjusted odds of post-CTS AF with higher intensity statin dosing versus the combined "no therapy plus low intensity" group (adjusted odds ratio $=0.60$ ) were similar to the odds for the lower intensity group alone (adjusted odds ratio $=0.71$, suggesting that it is a power issue. Although this may be why we showed a $40 \%$ reduction in the odds of post-CTS AF compared with the ARMYDA-3 study, which showed a $61 \%$ reduction with atorvastatin $40 \mathrm{mg}$ (a high-intensity therapy), we cannot exclude the possibility that our use of beta-blockers and amiodarone attenuated the benefits in our study or that the results were due to chance or population differences. The impact of dosing intensity on results is clearly the most important area for future research because most patients with coronary disease receive statin therapy, but very few receive high-intensity therapy. ${ }^{26}$ Further research using randomized controlled trials will clearly be needed to answer this.

\section{Conclusions}

In patients with appreciable prophylactic use of betablockers and amiodarone, preoperative statin administration may still be beneficial in reducing the incidence of AF after CTS.

\section{References}

1. Thom T, Haase N, Rosamond W, et al. Heart disease and stroke statistics-2006 update: a report from the American Heart Association Statistics Committee and Stroke Statistics Subcommittee. Circulation. 2006;113:e85-151.

2. Almassi GH, Schowalter T, Nicolosi AC, et al. Atrial fibrillation after cardiac surgery: a major morbid event? Ann Surg. 1997;226:501-11.

3. Mathew JP, Fontes ML, Tudor IC, et al. A multicenter risk index for atrial fibrillation after cardiac surgery. JAMA. 2004;291:1720-9.

4. Burgess DC, Kilborn MJ, Keech AC. Interventions for prevention of post-operative atrial fibrillation and its complications after cardiac surgery: a meta-analysis. Eur Heart J. 2006;27:2846-57.

5. Bagshaw SM, Galbraith PD, Mitchell LB, et al. Prophylactic amiodarone for prevention of atrial fibrillation after cardiac surgery: a meta-analysis. Ann Thorac Surg. 2006;82:1927-37.

6. Giri S, White CM, Dunn AB, et al. Oral amiodarone for prevention of atrial fibrillation after open heart surgery, the Atrial Fibrillation Suppression Trial (AFIST): a randomised placebo-controlled trial. Lancet. 2001; 357:830-6.

7. White CM, Caron MF, Kalus JS, et al. Intravenous plus oral amiodarone, atrial septal pacing, or both strategies to prevent post-cardiothoracic surgery atrial fibrillation: the Atrial Fibrillation Suppression Trial II (AFIST II). Circulation. 2003;108:200-6.

8. Aviles RJ, Martin DO, Apperson-Hansen C, et al. Inflammation as a risk factor for atrial fibrillation. Circulation. 2003;108:3006-10. 
9. Bruins P, te Velthuis H, Yazdanbakhsh AP, et al. Activation of the complement system during and after cardiopulmonary bypass surgery: postsurgery activation involves C-reactive protein and is associated with postoperative arrhythmia. Circulation. 1997;96:3542-8.

10. Chung MK, Martin DO, Sprecher D, et al. C-reactive protein elevation in patients with atrial arrhythmias: inflammatory mechanisms and persistence of atrial fibrillation. Circulation. 2001;104:2886-91.

11. Gaudino M, Andreotti F, Zamparelli R, et al. The $-174 \mathrm{G} / \mathrm{C}$ interleukin-6 polymorphism influences postoperative interleukin-6 levels and postoperative atrial fibrillation. Is atrial fibrillation an inflammatory complication? Circulation. 2003;108(Suppl):II195-9.

12. Jialal I, Stein D, Balis D, et al. Effect of hydroxymethyl glutaryl coenzyme a reductase inhibitor therapy on high sensitive C-reactive protein levels. Circulation. 2001;103:1933-5.

13. Kumagai K, Nakashima H, Saku K. The HMG-CoA reductase inhibitor atorvastatin prevents atrial fibrillation by inhibiting inflammation in a canine sterile pericarditis model. Cardiovasc Res. 2004;62:105-11.

14. Plenge JK, Hernandez TL, Weil KM, et al. Simvastatin lowers C-reactive protein within 14 days: an effect independent of low-density lipoprotein cholesterol reduction. Circulation. 2002;106:1447-52.

15. Dotani MI, Elnicki DM, Jain AC, et al. Effect of preoperative statin therapy and cardiac outcomes after coronary artery bypass grafting. Am J Cardiol. 2000;86:1128-30.

16. Marin F, Pascual DA, Roldan V, et al. Statins and postoperative risk of atrial fibrillation following coronary artery bypass grafting. Am J Cardiol. 2006;97:55-60.

17. Ozaydin M, Dogan A, Varol E, et al. Statin use before by-pass surgery decreases the incidence and shortens the duration of postoperative atrial fibrillation. Cardiology. 2006;107:117-21.

18. Patti G, Chello M, Candura D, et al. Randomized trial of atorvastatin for reduction of postoperative atrial fibrillation in patients undergoing cardiac surgery: results of the ARMYDA-3 (Atorvastatin for Reduction of MYocardial Dysrhythmia After cardiac surgery) study. Circulation. 2006;114:1455-61.

19. White CM, Sander S, Coleman CI, et al. Impact of epicardial anterior fat pad retention on post-cardiothoracic surgery atrial fibrillation incidence: The Atrial Fibrillation Suppression Trial III (AFIST III). J Am Coll Cardiol. 2007;49:298-303.

20. Jones PH, Davidson MH, Stein EA, et al. Comparison of the efficacy and safety of rosuvastatin versus atorvastatin, simvastatin, and pravastatin across doses. Am J Cardiol. 2003;92:152-60.

21. White CM, Chow MSS. A review of HMG CoA reductase inhibitors. US Pharmacist. 1998;22:HS19-HS28.

22. Physicians Desk Reference (PDR). Cardiovascular prescribing guide, 4th ed. Montvale, NJ: Medical Economics Company; 2000.

23. Crystal E, Connolly SJ, Sleik K, et al. Interventions on prevention of postoperative atrial fibrillation in patients undergoing heart surgery: a meta-analysis. Circulation. 2002; 106:75-80.

24. Fuster V, Ryden LE, Cannon DS, et al. ACC/AHA/ESC 2006 guidelines for the management of patients with atrial fibrillation: full text: a report of the American College of Cardiology/American Heart Association Task Force on practice guidelines and the European Society of Cardiology Committee for Practice Guidelines (Writing Committee to Revise the 2001 guidelines for the management of patients with atrial fibrillation) developed in collaboration with the European Heart Rhythm Association and the Heart Rhythm Society. Europace. 2006;8:651-745.

25. Brull DJ, Sanders J, Rumley A, et al. Statin therapy and the acute inflammatory response after coronary artery bypass grafting. Am J Cardiol. 2001;88:431-3.

26. White CM. Ensuring that patients receive full cardiac pharmacotherapy services: a pharmacist's call to arms. Ann Pharmacother. 2006;40: $2248-50$.

The Journal of Thoracic and Cardiovascular Surgery Conflict of Interest Policy

To assure fairness to authors submitting work for consideration in The Journal of Thoracic and Cardiovascular Surgery, a mechanism exists for managing conflicts of interest. The editor and each of the section editors complete a "Conflict of Interest" form that identifies any and all relationships with commercial and other academic entities. When the editor has a potential conflict because of a relationship with another entity or author, the editor appoints an alternate editor from among the section editors or editorial board members who assumes the entire responsibility for final decisions on the manuscript in question. The editor does not read the reviews that are submitted nor engage in discussing the manuscript prior to the final decision. When the conflict of interest involves a section editor, a "guest section editor" is appointed who fills the role normally played by the conflicted section editor. All members of the editorial board and reviewers are asked to indicate any conflict of interest when they agree to review a manuscript. 